\section{(2) OPEN ACCESS}

\title{
Household use of crop residues and fuelwood for cooking and newborn birth size in rural Bangladesh
}

\author{
Mi-Sun Lee (i) , ${ }^{1}$ Ki-Do Eum, ${ }^{2}$ Mostofa Golam, ${ }^{3}$ Quazi Quamruzzaman, ${ }^{3}$ Molly L Kile, ${ }^{4}$ \\ Maitreyi Mazumdar, ${ }^{1,5}$ David C Christiani (1) ${ }^{1,6}$
}

\begin{abstract}
- Additional supplemental material is published online only. To view, please visit the journal online (http://dx.doi. org/10.1136/oemed-2021 107908)
\end{abstract}

${ }^{1}$ Department of Environmental Health, Harvard T.H. Chan School of Public Health, Boston, Massachusetts, USA

${ }^{2}$ Department of Civil and Environmental Engineering, Tufts University, Medford, Massachusetts, USA

${ }^{3}$ Dhaka Community Hospital Trust, Dhaka, Bangladesh ${ }^{4}$ College of Public Health and Human Sciences, Oregon State University, Corvallis, Oregon, USA

${ }^{5}$ Department of Neurology, Boston Children's Hospital, Boston, Massachusetts, USA ${ }^{6}$ Massachusetts General Hospital, Boston, Massachusetts, USA

\section{Correspondence to}

Dr Mi-Sun Lee, Department of Environmental Health, Harvard TH Chan School of Public Health, Boston, Massachusetts USA; mslee@hsph.harvard.edu

Received 22 July 2021

Accepted 29 January 2022

\section{ABSTRACT \\ Objectives We aimed to investigate the association} between type of cooking biomass fuels (crop residues vs fuelwood) and newborn birth outcomes in Bangladeshi children.

Methods In this birth cohort study, pregnant women who were 18 years or older with ultrasound confirmed singleton pregnancy of $\leq 16$ weeks of gestation were enrolled from two Bangladesh clinics between January 2008 and June 2011. Exposure to cooking biomass fuels during pregnancy was assessed by an administered questionnaire. The newborn size metrics were measured at the time of delivery. We used multiple linear regression and logistic regression to assess the associations between the type of cooking biomass fuels and birth outcomes after adjusting for covariates.

Results A total of 1137 participants were using biomass fuels, including crop residues (30.3\%) and fuelwood $(69.7 \%)$, respectively, for cooking. After adjusting for covariates, the use of crop residues for cooking was associated with a 0.13 SD decrease in birth length $(95 \% \mathrm{Cl} 0.25$ to -0.01$)$, a 0.14 SD decrease in head circumference $(95 \% \mathrm{Cl}-0.27$ to -0.02$)$, and increased risk of low birth weight (LBW, OR 1.52, 95\% Cl 1.07 to 2.15) compared with the use of fuelwood.

Conclusion The use of crop residues for cooking was associated with reduced birth size and increased risk for LBW in Bangladeshi children, implying that the use of crop residues during pregnancy may have a detrimental effect on fetal growth.

\section{INTRODUCTION}

Of the 7.7 billion world population, about 3 billion people (41\% of households) still use solid fuels, defined as coal and biomass (wood, crop residues, dung or charcoal), and kerosene for cooking, mainly in rural areas in low-income countries. The combustion of household solid fuels releases various health-damaging pollutants such as respirable particulate matter (PM), black carbon, carbon monoxide, polycyclic aromatic hydrocarbons (PAHs), heavy metals and many other organic pollutants. $^{2-5}$

Household air pollution from the use of solid fuels contributed to 3.8 million premature deaths per year. ${ }^{1}$ In 2019 , nearly two-thirds (64\%) of the 500000 neonatal deaths in the first month of their life were attributable to household use of solid fuels for cooking. ${ }^{6}$ Especially women of reproductive age, who were mainly involved in cooking activity, and their young children under 5 years are faced

\section{Key messages}

What is already known about this subject?

- More than $90 \%$ of households still use biomass for cooking in rural Bangladesh; few epidemiological studies have examined the association between the type of traditional cooking biomass fuels (crop residues vs fuelwood) and birth outcomes.

\section{What are the new findings?}

-We found that the use of crop residues for cooking was associated with reduced birth size and higher risk of low birth weight in Bangladeshi children.

How might this impact on policy or clinical practice in the foreseeable future?

- Prenatal exposure to cooking biomass fuel, crop residues in particular, may be toxic to fetal growth; switching to cleaner fuels is an important approach to reduce adverse birth outcomes.

with the highest PM exposure from biomass fuels in homes ${ }^{78}$ and the burden of deaths from biomass exposure. $^{9} 10$

Studies have linked cooking solid fuel use with adverse birth outcomes such as low birth weight (LBW), birth size, preterm birth, stillbirth, small for gestational age (SGA), Apgar score and neonatal mortality. ${ }^{11-23}$ Most of previous studies have focused mainly on the association between the use of solid fuels and birth outcomes by comparing pollution fuels (wood, crop residue, animal dung, charcoal or kerosene) versus cleaner fuels (liquid petroleum gas, natural gas and/or electricity). ${ }^{12}{ }^{14-17}{ }^{19-23}$ However, to our knowledge, no studies have accessed the type of cooking biomass fuels (crop residues vs fuelwood, also called 'firewood') in association with newborn birth outcomes such as birth size and LBW, even though the pollution exposure from biomass was different by type of cooking biomass fuels. ${ }^{24}$ This research gap is more substantial in Bangladesh as well as many low-income countries in rural South Asia, the highest LBW-prevalent region ${ }^{25}$ where these biomass fuels have been predominantly used for cooking. ${ }^{26} 27$

Therefore, in this birth cohort study, we assessed the association between the type of cooking biomass fuels (crop residues vs fuelwood) and neonate size 
metrics (birth weight, birth length and head circumference), LBW, preterm birth, SGA and large for gestational age (LGA) in a community-based sample recruited from rural Bangladesh where over $90 \%$ of cooking energy was derived from biomass fuels. ${ }^{27}$

\section{METHODS}

\section{Study design and birth cohort}

The Jeebon (meaning 'life' in Bengali) cohort is a communitybased, prospective birth cohort study, which was established in 2008 in two rural clinics of Dhaka Community Hospital (DCH), located in Pabna Upazila and Sirajdikhan Upazila of Bangladesh. The study population has been described. ${ }^{28-31}$ Briefly, 1613 pregnant women with an ultrasound-confirmed singleton pregnancy $\leq 16$ weeks of gestation that resulted in a live birth were enrolled in the cohort between January 2008 and June 2011. Women were followed up throughout their pregnancies. Participants provided sociodemographic, medical and environmental data as well as birth outcome data at delivery. The demographic and environmental information, including sociodemographic factors (age, infant gender and household income), smoking history (smoking status and secondhand smoke (SHS)) and household biomass fuel exposures was collected using a structured questionnaire at scheduled clinic visits during pregnancy. Of the 1167 participants with singleton live births, missing information on household income $(n=8)$, SHS $(n=1)$, and the type of biomass fuels and time spent cooking $(n=8)$ were excluded. Of the 1150 participants, women using bottled gas and animal dung for cooking biomass fuel $(n=13)$ were excluded. Finally, a total of 1137 participants were included in the analysis.

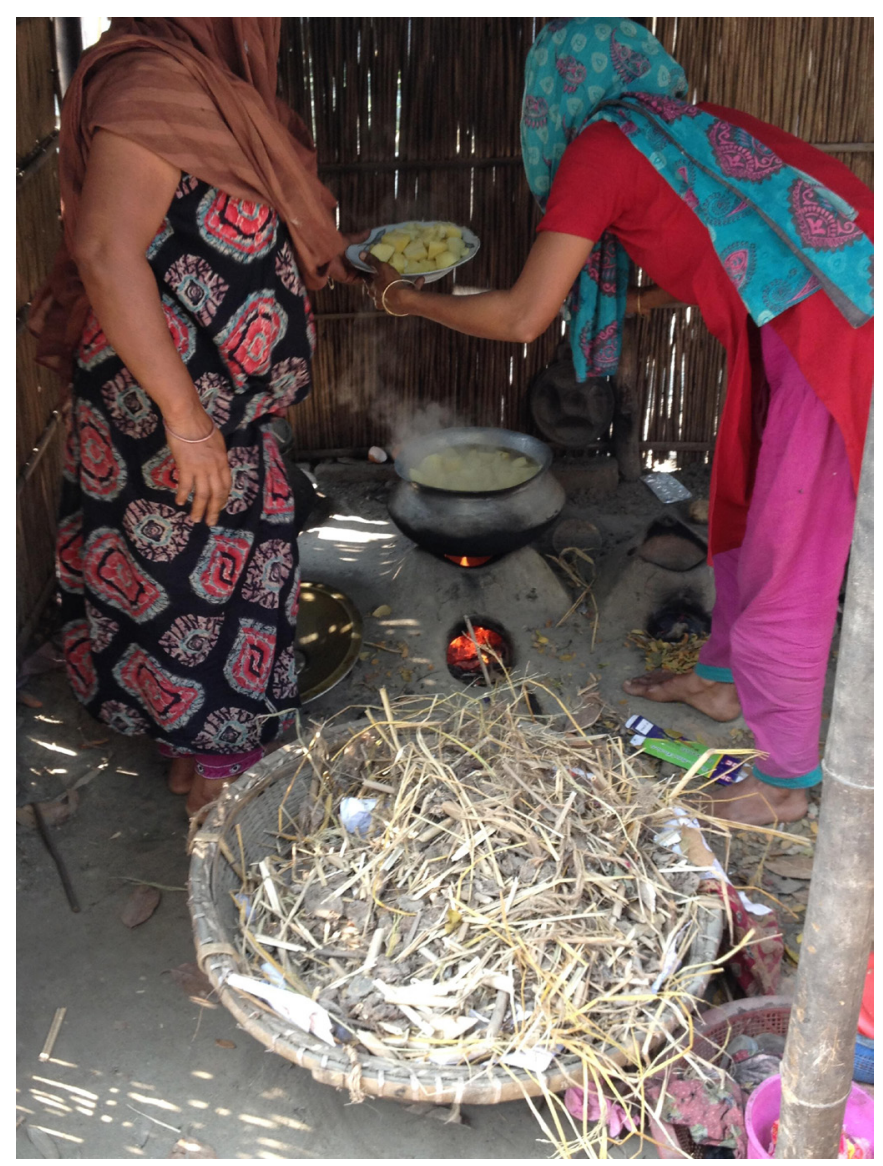

Figure 1 Cooking over a traditional mud stove using crop residue in Bangladesh, 2008 (photo credit: Molly L Kile).

\section{Exposure data}

In the present population, pregnant women were cooking over a traditional mud stove in a rural village home in Bangladesh (figure 1). Maternal exposure to biomass fuels from cooking was assessed in the questions at enrolment at $\leq 16$ weeks of pregnancy: type of cooking fuels (crop residues, fuelwood, bottled gas, animal dung and kerosene) by asking 'What type of fuel do you usually use for cooking?'. The pregnant women using bottled gas $(n=4)$, kerosene $(n=0)$ or animal dung $(n=9)$ for cooking were not included in the analysis due to a very small number of subjects. We compared crop residues versus fuelwood.

\section{Birth outcomes}

Newborns' anthropometric indicators (birth weight, birth length and head circumference) were assessed at the time of delivery by well-trained field staff from DCH clinics. ${ }^{28}$ Birth weight was recorded to the nearest $10 \mathrm{~g}$ using calibrated digital infant scales. ${ }^{32}$ Birth length was measured to the nearest $0.1 \mathrm{~cm}$ on an infantometer in a supine position with baby knees fully extended and the soles of the baby's feet held firmly against the measuring board. Head circumference was measured to the closest $0.1 \mathrm{~cm}$ at the maximal occipitofrontal circumference using a standard measuring tape. Birth gestational age (weeks) was estimated by ultrasound measurements taken at enrolment. ${ }^{31}$ Maternal weight gain during pregnancy $(\mathrm{kg} /$ week) was calculated by subtracting weight obtained before delivery from weight measured at the time of enrolment divided by the number of weeks of follow-up. ${ }^{31}$ We calculated $\mathrm{z}$-scores for the birth size measures that were standardised to the study population mean and SD for each week of gestational age. ${ }^{28}$

$$
\text { Zscore }=\frac{\text { Individual Value }- \text { Mean }}{\text { Standard Deviation }} .
$$

Therefore, we did not adjust for gestational age when modelling associations with birth outcome z-scores. The z-scores could not be estimated for birth weight and head circumference for two births (one birth was at 22 weeks of gestation and one was at 28 weeks of gestation), or for birth length for five births (one birth at 22 weeks of gestation, one at 28 weeks of gestation and three at 29 weeks of gestation with having the same birth length). Binary adverse birth outcomes included LBW (less than 2500 g), preterm birth (before 37 weeks of pregnancy), SGA (below the 10th percentile of birthweight $\mathrm{z}$-scores) and LGA (above the 90th percentile of birthweight z-scores).

\section{Covariates}

Trained DCH healthcare workers who lived in the local area administered questionnaires to collect information on participants' sociodemographic, lifestyle and environmental information at their first clinical visit at enrolment at $\leq 16$ weeks of pregnancy. Maternal weight and height were measured at scheduled clinic visits during pregnancy. Covariates were selected a priori based on previous literature and plausible associations with birth outcomes ${ }^{28-30}$ including maternal age (years), maternal body mass index (BMI) at enrolment $\left(\mathrm{kg} / \mathrm{m}^{2}\right)$, infant sex, monthly household income (taka), SHS exposure during pregnancy (yes or no), study site (Pabna vs Sirajdikhan) and time spent cooking per day (hour/day). None of the participants smoked during pregnancy, but 42\% reported SHS exposure. ${ }^{28} 29$ We also adjusted for gestational age at birth (weeks) for analyses of unstandardised (raw) birth size measures (birth weight (g), birth length $(\mathrm{cm})$ and head circumference $(\mathrm{cm}))$ to provide absolute changes in birth outcomes. 


\begin{tabular}{|c|c|}
\hline Variables & $\mathrm{n}(\%)$ or mean $\pm \mathrm{SD}$ \\
\hline \multicolumn{2}{|l|}{ Maternal characteristics } \\
\hline Age at delivery (years) & $23.0 \pm 4.2$ \\
\hline BMI at enrolment $\left(\mathrm{kg} / \mathrm{m}^{2}\right)$ & $20.4 \pm 3.2$ \\
\hline \multicolumn{2}{|l|}{ Monthly household income (taka) } \\
\hline$\leq 3000$ & $193(17.0)$ \\
\hline $3001-4000$ & $304(26.7)$ \\
\hline $4001-5000$ & $340(29.9)$ \\
\hline $5001-6000$ & $169(14.9)$ \\
\hline$>6000$ & $131(11.5)$ \\
\hline \multicolumn{2}{|c|}{ Secondhand smoke exposure during pregnancy } \\
\hline Yes & $478(42.0)$ \\
\hline No & $659(58.0)$ \\
\hline \multicolumn{2}{|l|}{ Study site } \\
\hline Pabna & $560(49.2)$ \\
\hline Sirajdikhan & $577(50.8)$ \\
\hline \multicolumn{2}{|l|}{ Type of cooking biomass fuel } \\
\hline Crop residues & $344(30.3)$ \\
\hline Fuelwood & $793(69.7)$ \\
\hline Time spent cooking, per day & $2.5 \pm 0.7$ \\
\hline \multicolumn{2}{|l|}{ Neonatal characteristics } \\
\hline Gestational age at birth (weeks) & $38.0 \pm 1.9$ \\
\hline Birth weight (g) & $2837 \pm 408$ \\
\hline Birth length $(\mathrm{cm})$ & $46.6 \pm 2.4$ \\
\hline Head circumference $(\mathrm{cm})^{*}$ & $32.7 \pm 1.2$ \\
\hline \multicolumn{2}{|l|}{ Birth gender } \\
\hline Male & $571(50.2)$ \\
\hline Female & $566(49.8)$ \\
\hline \multicolumn{2}{|l|}{ Low birth weight } \\
\hline Yes & $187(16.5)$ \\
\hline No & $950(83.5)$ \\
\hline \multicolumn{2}{|l|}{ Preterm birth } \\
\hline Yes & $250(22.0)$ \\
\hline No & $887(78.0)$ \\
\hline \multicolumn{2}{|l|}{ SGA } \\
\hline Yes & $213(20.1)$ \\
\hline No & $846(79.9)$ \\
\hline \multicolumn{2}{|l|}{ LGA } \\
\hline Yes & $74(8.0)$ \\
\hline No & $846(92.0)$ \\
\hline
\end{tabular}

SGA excludes LGA, and LGA excludes SGA.

${ }^{*} \mathrm{~N}=1136$ due to missing data.

LGA, large for gestational age; SGA, small for gestational age.

\section{Statistical analysis}

Descriptive statistics were examined for all variables. Demographic differences between the type of cooking biomass fuels (crop residues vs fuelwood) were tested using logistic regression. Adjusted associations between the type of cooking biomass fuels and birth size z-scores and raw birth size measures were estimated using multiple linear regression. For the analysis of the raw value of birth size measures (birth weight $(\mathrm{g})$, birth length $(\mathrm{cm})$, and head circumference $(\mathrm{cm})$ ), gestational age (weeks) was additionally included. Associations between the type of cooking biomass fuels and adverse birth outcomes, including LBW, preterm birth, SGA and LGA, were analysed using logistic regression. All models were adjusted for maternal age (years), infant gender, maternal BMI at enrolment $\left(\mathrm{kg} / \mathrm{m}^{2}\right)$, monthly household income (taka), SHS exposure (yes vs no), time spent cooking (hour/day) and study site (Pabna vs Siradikhan). As a sensitivity analysis, we additionally adjusted for pregnancy weight gain in the regression models to examine the robustness of our results. To assess the potential effect modification by time spent cooking and SHS, we assessed the association between the type of cooking fuel and birth size outcomes, stratified by time spent cooking (median 2.5 hours, $\leq 2.5$ vs $>2.5$ ) and SHS (yes vs no). The $p$ values for interaction were estimated using the interaction terms, the product of type of cooking fuel (crop residues vs fuelwood) and time spent cooking ( $\leq 2.5 \mathrm{vs}>2.5$ ) or SHS (yes vs no) in the multiple regression model along with the main effects. Statistical analyses were performed using SAS V.9.4. The $p$ value for significance was $<0.05$.

\section{RESULTS}

Demographic and clinical characteristics stratified by type of cooking biomass fuel are given in table 1 . The overall study population included 1137 participants (mean age at delivery 23.0 (SD 4.2) years, mean BMI at enrolment 20.4 (SD 3.2), 571 (SD 50.2\%) male baby). Average infant sizes at birth were $2837 \mathrm{~g}$ (SD 408) for birth weight, $46.6 \mathrm{~cm}$ (SD 2.4) for birth length and $32.7 \mathrm{~cm}$ (SD 1.2) for head circumference. Overall, 187 (16.5\%) newborns had LBW and $250(22 \%), 213(20 \%)$ and $74(8 \%)$ had preterm birth, SGA and LGA. Overall, $344(30.3 \%)$ and 793 $(69.7 \%)$ women used crop residues and fuelwood for cooking during pregnancy.

Table 2 shows covariates and outcomes, stratified by crop residues and fuelwood. Statistically significant differences between users of crop residues and fuelwood were found in maternal age, BMI, household income, SHS, and study site.

The adjusted associations of type of cooking biomass fuels (crop residues vs fuelwood) with birth size outcomes are shown in table 3. When adjusted for covariates, the use of crop residues was associated with a 0.11 SD decrease in birth weight $(95 \% \mathrm{CI}$ -0.24 to 0.02$), 0.13$ SD decrease in birth length $(95 \% \mathrm{CI}-0.25$ to -0.01$)$ and a $0.14 \mathrm{SD}$ decrease in head circumference $(95 \% \mathrm{CI}$ -0.27 to -0.02 ) compared with women using fuelwood. Similar associations were observed with the raw value of birth size outcomes.

Table 4 presents the associations between cooking biomass fuels and adverse birth outcomes. The use of crop residues was associated with increased risk for LBW (OR: 1.52, 95\% CI: $1.07,2.15)$ compared with fuelwood users. No associations for preterm birth (OR: 0.81, 95\% CI: 0.58, 1.13), SGA (OR: 1.13, 95\% CI: $0.80,1.59)$ and LGA (OR: $1.01,95 \%$ CI: $0.58,1.75)$ were observed in crop residue users compared with fuelwood users.

As a sensitivity analysis, we analysed the data with additional adjustment for pregnancy weight gain as a potential confounder in the regression models and found similar associations (online supplemental table 1). We also assessed the potential effect modification by time spent cooking and the SHS and found there were no significant effect modifications (online supplemental table $2, \mathrm{p}$ value for interactions $>0.05$ ) .

\section{DISCUSSION}

In this birth cohort study, we found the association between the use of crop residues for cooking and decreases in birth length and head circumference and increased risk of LBW. These associations remain robust when we adjusted additionally for maternal weight gain during pregnancy.

To our knowledge, no studies have examined the association between type of cooking biomass fuels (crop residues vs fuelwood) 
Table 2 Characteristics of the study population by type of cooking biomass fuels, $\mathrm{N}=1137$

\begin{tabular}{|c|c|c|c|}
\hline \multirow[b]{2}{*}{ Variables } & \multirow{2}{*}{$\begin{array}{l}\text { Crop residues } \\
(\mathrm{n}=344) \\
\mathrm{n}(\%) \text { or mean } \pm S D\end{array}$} & \multirow{2}{*}{$\begin{array}{l}\text { Fuelwood } \\
(n=793)\end{array}$} & \multirow[b]{2}{*}{$P$ value* } \\
\hline & & & \\
\hline Age at delivery (years) & $23.4 \pm 4.5$ & $22.8 \pm 4.1$ & 0.03 \\
\hline \multicolumn{4}{|l|}{ Birth gender } \\
\hline Male & $177(51.4)$ & 394 (49.7) & 0.58 \\
\hline Female & $167(48.6)$ & $399(50.3)$ & \\
\hline $\begin{array}{l}\text { BMI at enrolment } \\
\left(\mathrm{kg} / \mathrm{m}^{2}\right)\end{array}$ & $19.8 \pm 2.9$ & $20.8 \pm 3.3$ & $<0.001$ \\
\hline \multicolumn{4}{|l|}{$\begin{array}{l}\text { Monthly household } \\
\text { income (taka) }\end{array}$} \\
\hline$\leq 3000$ & $85(24.7)$ & $108(13.6)$ & $<0.01$ \\
\hline $3001-4000$ & $95(27.6)$ & 209 (26.4) & 0.40 \\
\hline $4001-5000$ & $94(27.3)$ & $246(31.0)$ & 0.54 \\
\hline $5001-6000$ & $45(13.1)$ & $124(15.6)$ & 0.42 \\
\hline$>6000$ & $25(7.3)$ & $106(13.4)$ & Reference \\
\hline \multicolumn{4}{|l|}{$\begin{array}{l}\text { Secondhand smoke } \\
\text { exposure }\end{array}$} \\
\hline Yes & $166(48.3)$ & $312(39.3)$ & 0.01 \\
\hline No & $178(51.7)$ & $481(60.7)$ & Reference \\
\hline \multicolumn{4}{|l|}{ Study site } \\
\hline Pabna & $218(63.4)$ & $342(39.3)$ & $<0.001$ \\
\hline Sirajdikhan & $126(36.6)$ & $451(60.7)$ & Reference \\
\hline $\begin{array}{l}\text { Time spent cooking } \\
\text { (hour/day) }\end{array}$ & $2.5 \pm 0.8$ & $2.4 \pm 0.7$ & 0.68 \\
\hline Low birth weight & $83(24.1)$ & $104(13.1)$ & $<0.01$ \\
\hline Preterm birth & $82(23.8)$ & $168(21.2)$ & 0.32 \\
\hline SGA & $72(23.0)$ & $140(18.9)$ & 0.13 \\
\hline LGA & $25(9.3)$ & $49(7.5)$ & 0.38 \\
\hline
\end{tabular}

SGA excludes LGA, and LGA excludes SGA.

${ }^{*} \mathrm{P}$ value for comparing the difference between users of crop residues versus fuelwood, given by logistic regression analysis.

LGA, large for gestational age; SGA, small for gestational age.

and newborn size and adverse birth outcomes. Although direct comparison is limited, most of the previous studies have reported associations of solid fuel use with LBW and/or reduced birth weight in Bangladesh, ${ }^{15}{ }^{17}$ Pakistan, ${ }^{22}$ Zimbabwe $^{23}$ and India ${ }^{20} 21$ when they compared with non-biomass fuels. In Bangladesh, an increased risk of LBW was found in coal or wood fuel users compared with electric/gas users. ${ }^{17}$ Similarly, indoor use of cooking solid fuel versus no use of indoor solid fuel was associated with increased risk for LBW (OR 1.33, 95\% CI 1.14 to
1.56), but no association was found with the fuel type (solid fuel vs clean fuel). ${ }^{15}$ In pregnant women from a semirural area of Pakistan, cooking with wood fuel during pregnancy was associated with LBW compared with using natural gas. ${ }^{22}$ In a study from rural Zimbabwe, cooking with biomass fuels (wood, dung and straw) was associated with a $175 \mathrm{~g}(95 \% \mathrm{CI}-300$ to $-50)$ decrease in mean birth weight compared with using lowpollution fuels (liquefied petroleum gas (LPG), natural gas or electricity). ${ }^{23}$ In a cross-sectional data from India's National Family Health Survey-3, the use of coal or biomass was associated with an increased risk of LBW and decrease in mean birth weight compared with using low-pollution fuel (LPG, natural gas and biogas). ${ }^{20}$ In the Demographic Health Survey in Malawi, a decrease in mean birth weight $(92 \mathrm{~g})$ was observed with the use of high-pollution fuels (charcoal, wood, crops, straw and dung), but it was not statistically significant. ${ }^{16}$ By contrast, findings were inconsistent in pregnant women in Ghana ${ }^{14}$ and central and east India. ${ }^{19}$ The use of high-pollution fuels (wood, charcoal, crop residues and kerosene) was associated with Apgar score below 7 at $5 \mathrm{~min}$, but no associations were found with LBW, preterm birth and SGA, probably due to the small number of cases. ${ }^{14}$ The use of wood for cooking was associated with an increased risk of preterm birth (OR 2.3, 95\% CI 1.2 to 4.2), but no associations were found with LBW, stillbirth and SGA. ${ }^{19}$ The aforementioned studies compared cooking fuels according to high-pollution fuels (wood, crop residue, animal dung, charcoal or kerosene) versus low-pollution fuels (LPG, natural gas or electricity), suggesting potential effect of biomass on adverse birth outcomes. Specifically, the present study compared the effect by type of cooking biomass fuels (crop residues vs fuelwood) and found that pregnant women using crop residues for cooking over a traditional mud stove during pregnancy had lighter (by $41 \mathrm{~g}$ ) and lower length (by $0.26 \mathrm{~cm}$ ) and smaller head circumference (by $0.17 \mathrm{~cm}$ ) of newborn babies and a higher risk of LBW (52\%) than women using fuelwood.

Although the greater effect of crop residues than fuelwood is not fully explainable, cooking activity, fuel mass, time, and composition of toxic chemicals from biomass burning may contribute to adverse birth outcomes. Crop residues are generally available at no or low cost, and the burning of crop residues is shorter than wood fuels, resulting in frequent refuelling in the cooking process. The burning of crop residues contributed to excessive pollution of $\mathrm{PM}_{2.5}{ }^{2} 33$ and $\mathrm{PAHs}^{3}$ that has been linked with birth outcomes. ${ }^{3435}$ In addition, crop residues typically have a higher content of ash and volatile matter, higher PM formation potential, black carbon, photochemical oxidant formation,

Table 3 Adjusted effect estimates ( $\beta$ and $95 \% \mathrm{Cls}$ ) for birth size outcomes in association with type of cooking biomass fuels

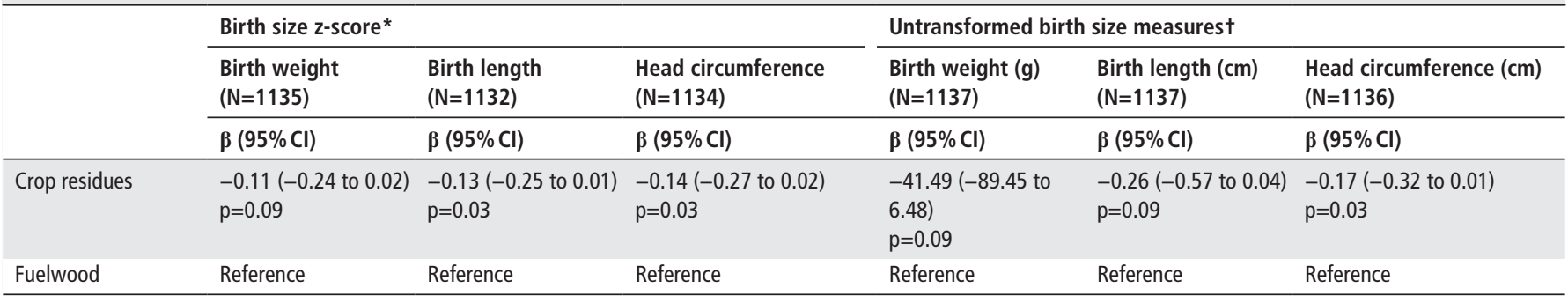

The $n$ 's differ in z-score outcomes: missing in birthweight $z$-score $(n=2)$ and head circumference $z$-score $(n=2)$ due to 22 weeks of gestation ( $n=1)$ and 28 weeks of gestation $(n=1)$, respectively, and missing in birth length z-score $(n=5)$ due to 22 weeks of gestation $(n=1)$, 28 weeks of gestation $(n=1)$ and 29 weeks of gestation $(n=3)$ with having the same value of birth length.

*Models adjusted for maternal age, maternal enrolment BMI, infant gender, income, SHS exposure, study site and time spent cooking per day. †Models adjusted for maternal age, maternal enrolment BMI, infant gender, income, SHS exposure, study site, time spent cooking per day and gestational age. BMI, body mass index; SHS, secondhand smoke. 


\begin{tabular}{|c|c|c|c|c|}
\hline & $\begin{array}{l}\text { LBW* }^{*} \\
\text { (187 vs 950) }\end{array}$ & $\begin{array}{l}\text { Preterm birth* } \\
\text { (250 vs } 887)\end{array}$ & $\begin{array}{l}S^{S G A}{ }^{*} \\
\text { (213 vs } 846)\end{array}$ & $\begin{array}{l}\text { LGA* }^{*} \\
\text { (74 vs 846) }\end{array}$ \\
\hline & OR $(95 \% \mathrm{Cl})$ & OR $(95 \% \mathrm{Cl})$ & OR $(95 \% \mathrm{Cl})$ & OR $(95 \% \mathrm{Cl})$ \\
\hline \multicolumn{5}{|c|}{ Cooking biomass fuelt } \\
\hline Crop residues & 1.52 (1.07 to 2.15$)$ & 0.81 (0.58 to 1.13$)$ & 1.13 (0.80 to 1.59$)$ & 1.01 (0.58 to 1.75$)$ \\
\hline Fuelwood & Reference & Reference & Reference & Reference \\
\hline
\end{tabular}

SGA excludes LGA, and LGA excludes SGA.

${ }^{*}$ Cases versus non-cases.

tModels adjusted for maternal age, maternal enrolment body mass index, infant gender, income, secondhand smoke exposure, time spent cooking and study site.

LGA, large for gestational age; SGA, small for gestational age.

lower stove efficiency and lower energy values compared with fuelwood. $^{2436}$

We observed no significant associations with preterm birth, SGA and LGA, similar to previous studies. ${ }^{14} 19$ It is likely that possibility of residual confounding could not be ruled out or the impact of crop residue may vary, depending on emission profile of cooking biomass fuels, cooking behaviours and birth outcomes. These findings need to be confirmed in larger observational studies.

In Bangladesh, almost all rural households use biomass fuels such as crop residues (jute, rice straw, etc) and fuelwood as their main source of cooking fuel as there is no commercial supply of gas in the rural areas. ${ }^{27}{ }^{37}$ Although further research for risk assessment, experiment interventions and policy development are needed, given that more than $90 \%$ of households are still using biomass for cooking in rural Bangladesh, switching to cleaner fuels in the sustainable energy policy may be the promising approach to prevent the excess burden of adverse birth outcomes in Bangladesh.

We acknowledge several limitations. First, household biomass fuel exposure assessment was based on a questionnaire, like many prior observational studies, potentially introducing exposure misclassification. Non-differential misclassification might dilute the true association. Second, we did not have information on the possible use of secondary fuels, cooking behaviours (eg, type of stoves uses), place of cooking, availability of separate kitchen, ventilation and anaemia status of mothers which were not accounted in the models. The potential for uncontrolled confounding cannot be ruled out in the present study. Third, the use of fuelwood as a comparison may have led to the underestimation of the effect of using biomass for cooking, as fuelwood is also biomass. However, this would bias towards null so that the actual effect size may be larger. Lastly, we recruited participants from two health clinics. These clinics are representative of this region but may not represent the general rural population in Bangladesh. Further studies with larger sample sizes are warranted to confirm our findings.

\section{CONCLUSIONS}

In conclusion, the use of crop residues versus fuelwood for cooking was associated with reduced newborn birth size and increased risk of LBW in rural Bangladeshi children.

Our findings suggest that prenatal exposure to traditional cooking biomass fuel, crop residues in particular, may be more toxic to fetal growth than fuelwood in terms of birth size outcomes.

Acknowledgements The authors gratefully acknowledge the contribution of all participants in Bangladesh and the research team.
Contributors Concept and design: M-SL and DCC; data collection: MG, QQ, MLK and MM; data analysis and interpretation: M-SL, K-DE, MLK, MM and DCC; drafting of the manuscript: M-SL; critical revision of the manuscript: all authors; supervision: DCC; obtained funding: DCC; guarantor of the manuscript: M-SL

Funding This work was supported by the National Institute of Environmental Health Sciences of the National Institutes of Health (grant numbers: R01ES015533, P30ES000002, R01ES023441, K23017437 and R01ES026317).

Competing interests None declared.

Patient consent for publication Consent obtained directly from patient(s).

Ethics approval This study involves human participants and was approved by the human subjects committees at Harvard T.H. Chan School of Public Health and Dhaka Community Hospital Trust (protocol number P11351-118). Participants gave informed consent to participate in the study before taking part.

Provenance and peer review Not commissioned; externally peer reviewed.

Data availability statement Deidentified data are available on reasonable request. Individuals or groups who would like to use the data to address specific scientific questions must provide a proposal to the study principal investigator (DCC, email: dchris@hsph.harvard.edu) for full consideration. For more information, please email at mslee@hsph.harvard.edu.

Supplemental material This content has been supplied by the author(s). It has not been vetted by BMJ Publishing Group Limited (BMJ) and may not have been peer-reviewed. Any opinions or recommendations discussed are solely those of the author(s) and are not endorsed by BMJ. BMJ disclaims all liability and responsibility arising from any reliance placed on the content. Where the content includes any translated material, BMJ does not warrant the accuracy and reliability of the translations (including but not limited to local regulations, clinical guidelines, terminology, drug names and drug dosages), and is not responsible for any error and/or omissions arising from translation and adaptation or otherwise.

Open access This is an open access article distributed in accordance with the Creative Commons Attribution Non Commercial (CC BY-NC 4.0) license, which permits others to distribute, remix, adapt, build upon this work non-commercially, and license their derivative works on different terms, provided the original work is properly cited, appropriate credit is given, any changes made indicated, and the use is non-commercial. See: http://creativecommons.org/licenses/by-nc/4.0/.

\section{ORCID iDs}

Mi-Sun Lee http://orcid.org/0000-0002-3106-220X

David C Christiani http://orcid.org/0000-0002-0301-0242

\section{REFERENCES}

1 World Health Organization. Household air pollution and health, 2021. Available: https://www.who.int/news-room/fact-sheets/detail/household-air-pollution-andhealth [Accessed 10 Dec 2021].

2 Shupler M, Hystad P, Birch A, et al. Household and personal air pollution exposure measurements from 120 communities in eight countries: results from the PURE-AIR study. Lancet Planet Health 2020;4:e451-62.

3 Shen G, Wang W, Yang Y, et al. Emissions of PAHs from indoor crop residue burning in a typical rural stove: emission factors, size distributions, and gas-particle partitioning. Environ Sci Technol 2011;45:1206-12.

4 Zhang JJ, Smith KR. Household air pollution from coal and biomass fuels in China: measurements, health impacts, and interventions. Environ Health Perspect 2007:115:848-55.

5 Rupakheti D, Kim Oanh NT, Rupakheti M, et al. Indoor levels of black carbon and particulate matters in relation to cooking activities using different Cook stove-fuels in rural Nepal. Energy for Sustainable Development 2019;48:25-33. 
6 Health Effects Institute. State of global air 2020. special report. Boston, MA: Health Effects Institute, 2020.

7 Ezzati M, Saleh H, Kammen DM. The contributions of emissions and spatial microenvironments to exposure to indoor air pollution from biomass combustion in Kenya. Environ Health Perspect 2000;108:833-9.

8 Dionisio KL, Howie SRC, Dominici F, et al. Household concentrations and exposure of children to particulate matter from biomass fuels in the Gambia. Environ Sci Technol 2012:46:3519-27.

9 Owili PO, Muga MA, Pan W-C, et al. Cooking fuel and risk of under-five mortality in 23 sub-Saharan African countries: a population-based study. Int J Environ Health Res 2017:27:191-204.

10 Balmes JR. Household air pollution from domestic combustion of solid fuels and health. J Allergy Clin Immunol 2019;143:1979-87.

11 Quinn AK, Adjei IA, Ae-Ngibise KA, et al. Prenatal household air pollutant exposure is associated with reduced size and gestational age at birth among a cohort of Ghanaian infants. Environ Int 2021;155:106659.

12 Kanno GG, Anbesse AT, Shaka MF, et al. Effect of biomass fuel use and kitchen location on maternal report of birth size: cross-sectional analysis of 2016 Ethiopian demographic health survey data. Public Health Pract 2021;2:100211.

13 Bickton FM, Ndeketa L, Sibande GT, et al. Household air pollution and under-five mortality in sub-Saharan Africa: an analysis of 14 demographic and health surveys. Environ Health Prev Med 2020;25:67.

14 Weber E, Adu-Bonsaffoh K, Vermeulen R, et al. Household fuel use and adverse pregnancy outcomes in a Ghanaian cohort study. Reprod Health 2020;17:29.

15 Khan MN, B Nurs CZ, Mofizul Islam M, et al. Household air pollution from cooking and risk of adverse health and birth outcomes in Bangladesh: a nationwide population-based study. Environ Health 2017;16:57.

16 Milanzi EB, Namacha NM. Maternal biomass smoke exposure and birth weight in Malawi: analysis of data from the 2010 Malawi demographic and health survey. Malawi Med J 2017;29:160-5.

17 Haider MR, Rahman MM, Islam F, et al. Association of low birthweight and indoor air pollution: biomass fuel use in Bangladesh. J Health Pollut 2016;6:18-25.

18 Amegah AK, Quansah R, Jaakkola JJK. Household air pollution from solid fuel use and risk of adverse pregnancy outcomes: a systematic review and meta-analysis of the empirical evidence. PLoS One 2014;9:e113920.

19 Wylie BJ, Coull BA, Hamer DH, et al. Impact of biomass fuels on pregnancy outcomes in central East India. Environ Health 2014:13:1.

20 Epstein MB, Bates MN, Arora NK, et al. Household fuels, low birth weight, and neonatal death in India: the separate impacts of biomass, kerosene, and coal. Int J Hyg Environ Health 2013;216:523-32.

21 Sreeramareddy CT, Shidhaye RR, Sathiakumar N. Association between biomass fuel use and maternal report of child size at birth--an analysis of 2005-06 India Demographic Health Survey data. BMC Public Health 2011;11:403.
22 Siddiqui AR, Gold EB, Yang $X$, et al. Prenatal exposure to wood fuel smoke and low birth weight. Environ Health Perspect 2008;116:543-9.

23 Mishra V, Dai X, Smith KR, et al. Maternal exposure to biomass smoke and reduced birth weight in Zimbabwe. Ann Epidemiol 2004;14:740-7.

24 Cashman S, Rodgers M, Huff M. Life-cycle assessment of cookstove fuels in India and China. Washington, DC: US Environmental Protection Agency, 2016.

25 Khan MMA, Mustagir MG, Islam MR, et al. Exploring the association between adverse maternal circumstances and low birth weight in neonates: a nationwide populationbased study in Bangladesh. BMJ Open 2020;10:e036162.

26 National Institute of Population Research and Training (NIPORT). Bangladesh demographic and health survey 2017-18. Dhaka, Bangladesh, and Rockville, MD: NIPORT: Mitra and Associates, and ICF International), 2020.

27 Hassan MK, Halder P, Pelkonen P, et al. Rural households' preferences and attitudes towards biomass fuels - results from a comprehensive field survey in Bangladesh. Energy Sustain Soc 2013;3:24.

28 Lee M-S, Eum K-D, Golam M, et al. Umbilical cord blood metal mixtures and birth size in Bangladeshi children. Environ Health Perspect 2021;129:57006.

29 Gao S, Lin P-I, Mostofa G, et al. Determinants of arsenic methylation efficiency and urinary arsenic level in pregnant women in Bangladesh. Environ Health 2019;18:94

30 Rahman ML, Valeri L, Kile ML, et al. Investigating causal relation between prenatal arsenic exposure and birthweight: are smaller infants more susceptible? Environ Int 2017; 108:32-40

31 Kile ML, Cardenas A, Rodrigues E, et al. Estimating effects of arsenic exposure during pregnancy on perinatal outcomes in a Bangladeshi cohort. Epidemiology 2016:27:173-81.

32 Zota AR, Ettinger AS, Bouchard $M$, et al. Maternal blood manganese levels and infant birth weight. Epidemiology 2009:20:367-73.

33 Rahman MM, Begum BA, Hopke PK, et al. Assessing the PM $_{2.5}$ impact of biomass combustion in megacity Dhaka, Bangladesh. Environ Pollut 2020;264:114798.

34 Liang Z, Yang Y, Qian Z, et al. Ambient PM 2 and birth outcomes: Estimating the association and attributable risk using a birth cohort study in nine Chinese cities. Environ Int 2019:126:329-35.

35 Yang $\mathrm{P}$, Gong Y-J, Cao W-C, et al. Prenatal urinary polycyclic aromatic hydrocarbon metabolites, global DNA methylation in cord blood, and birth outcomes: a cohort study in China. Environ Pollut 2018;234:396-405.

36 International Agency for Research on Cancer. IARC Working group on the evaluation of carcinogenic risks to humans. household use of solid fuels and high-temperature frying. Lyon, FR: International Agency for Research on Cancer; (IARC Monographs on the Evaluation of Carcinogenic Risks to Humans, No. 95.), 2010. https://www.ncbi. nlm.nih.gov/books/NBK385523/

37 Huda ASN, Mekhilef S, Ahsan A. Biomass energy in Bangladesh: current status and prospects. Renewable and Sustainable Energy Reviews 2014:30:504-17. 